\title{
Simbolismo de las narigueras peruanas y aproximación a su manufactura durante el Periodo Intermedio Temprano
}

Symbologie des narigueras $p$

ruviennes et premi

re approche

leur processus de fabrication pendant l'Interm

diaire Ancien

Symbology of Peruvian nose ornaments (narigueras) and a first approach to their manufacturing process during the Early Intermediate Period

Luisa Vetter Parodi y Maria Filomena Guerra

\section{(2) OpenEdition}

Journals

Edición electrónica

URL: http://journals.openedition.org/bifea/10543

DOI: $10.4000 /$ bifea. 10543

ISSN: 2076-5827

Editor

Institut Français d'Études Andines

\section{Edición impresa}

Fecha de publicación: 1 agosto 2019

Paginación: 109-133

ISSN: 0303-7495

\section{Referencia electrónica}

Luisa Vetter Parodi y Maria Filomena Guerra, "Simbolismo de las narigueras peruanas y

aproximación a su manufactura durante el Periodo Intermedio Temprano », Bulletin de l'Institut français d'études andines [En línea], 48 (2) | 2019, Publicado el 08 agosto 2019, consultado el 26 noviembre 2020. URL : http://journals.openedition.org/bifea/10543; DOI : https://doi.org/10.4000/bifea.10543 


\section{(c) $10 \otimes$}

Les contenus du Bulletin de l'Institut français d'études andines sont mis à disposition selon les termes de la licence Creative Commons Attribution - Pas d'Utilisation Commerciale - Pas de Modification 4.0 International. 


\title{
Simbolismo de las narigueras peruanas y aproximación a su manufactura durante el Periodo Intermedio Temprano
}

\author{
Luisa Vetter Parodi* \\ Maria Filomena Guerra**
}

\begin{abstract}
Resumen
Este trabajo presenta una visión general del significado e importancia que tuvieron las narigueras en las culturas peruanas precolombinas; asimismo las relaciona con las narigueras colombianas y mexicanas, y también nos introduce a su simbología. A partir de los ejemplares conocidos, se ha destacado la variedad de colores utilizados en su fabricación y, por tanto, la diversidad de tecnologías utilizadas. Para lograr un primer acercamiento a estas tecnologías, un corpus de 39 narigueras procedentes de distintas colecciones peruanas correspondientes al Periodo Intermedio Temprano (200 a. C.-600 d. C.) se analizó por medio de microscopia óptica y espectrometría de fluorescencia de rayos X por dispersión de energía con un equipo portátil. Con base en los resultados obtenidos, y por comparación entre los porcentajes de plata, oro y cobre contenidos en las aleaciones de las narigueras bicolores y monocolores, fue posible deducir cómo fueron elaboradas.
\end{abstract}

Palabras clave: narigueras, Periodo Intermedio Temprano, uso, tecnologías, aleaciones

* Pontificia Universidad Católica del Perú y Academia Nacional de Ciencias, Av General Ernesto Montagne 170, Dpto 202. Urbanización Aurora, Miraflores-Perú. E-mail: luchivetter@hotmail.com

${ }^{* *}$ Maria Filomena Guerra. MONARIS, UMR 8233 CNRS - Sorbonne Université, 4 Place de Jussieu, 75252 Paris Cedex 05, Francia. E-mail: maria.guerra@cnrs.fr 


\title{
Symbologie des narigueras péruviennes et première approche de leur processus de fabrication pendant l'Intermédiaire Ancien
}

\author{
Résumé
}

Ce travail donne un aperçu de l'importance et de la signification des anneaux de nez (narigueras) pour les cultures précolombiennes du Pérou. Nous avons associé ces nariqueras à celles produites en Colombie et au Mexique et discuté de leur symbologie. À partir des exemplaires connus, nous avons mis en évidence la variété de leurs couleurs et, par conséquent, la diversité des technologies utilisées pour leur fabrication. Pour une première approche de ces technologies, 39 narigueras appartenant à plusieurs collections péruviennes, datées de I'Intermédiaire Ancien (200 av. J.-C.-600 apr. J.-C.), ont été étudiées par microscopie optique et spectrométrie de fluorescence $X$ à dispersion en énergie, avec un équipement portable. En utilisant les données obtenues, et par comparaison entre les quantités d'argent, d'or et de cuivre dans les alliages, nous avons pu établir l'utilisation de différentes technologies pour la production de narigueras à une ou deux couleurs.

Mots clés : narigueras, Intermédiaire Ancien, utilisation, technologies, alliages

\section{Symbology of Peruvian nose ornaments (narigueras) and a first approach to their manufacturing process during the Early Intermediate Period}

\section{Summary}

This work provides an overview of the importance and meaning of nose rings (narigueras) for the PreColumbian cultures of Peru. We related these ornaments with the nose rings produced in Colombia and Mexico and discussed their symbolism. Based on the known narigueras, we outlined the variety of their colors and the diversity of technologies employed in their manufacture. In this first approach to this production technology, 39 narigueras in several Peruvian collections, dated to the Early Intermediate Period (circa 200 AD-600 AD), were studied using optical microscopy and energy dispersive X-ray fluorescence spectrometry, with a handheld equipment. By using the data obtained, including the silver, gold and copper amounts in the alloys, we establish the use of different technologies for the production of both the single-color and the bicolor narigueras.

Key words: nose ornaments, nose rings, narigueras, Early Intermediate Period, use, technologies, alloys

\section{INTRODUCCIÓN}

En el territorio andino las narigueras se conocen y utilizan desde el Horizonte Temprano (900-200 a. C.), pero no aparecen en el registro arqueológico de manera continua pues, como veremos, hay periodos en los que no hay evidencias de su uso. Estos objetos eran colocados en la nariz y cubrían la boca de las personas que los portaban, generalmente individuos pertenecientes a la élite. Las narigueras podían ser llanas o decoradas con una rica iconografía, además de otros elementos 
como lentejuelas unidas mecánicamente y que producían diversos sonidos con el movimiento. Se confeccionaban en oro o plata, y a veces se elaboraban con una combinación de ambos metales preciosos.

En estas páginas presentamos varias interpretaciones sobre el significado que las narigueras tuvieron en las culturas precolombinas peruanas, haciendo además un recorrido descriptivo por las investigaciones realizadas en otras zonas americanas como Colombia y México.

Asimismo, en este estudio se plantean diversas formas de elaboración de las narigueras precolombinas peruanas que datan del Periodo Intermedio Temprano (200 a. C.-600 d. C.), puesto que existe una gran cantidad de estas piezas en diversas colecciones.

Tanto Hörz \& Kallfass (1998) como Cesareo et al. (2016; 2017) han realizado estudios analíticos a algunas narigueras procedentes de contextos arqueológicos pertenecientes a Sipán y a la Señora de Cao; en ambos casos estos objetos se enmarcan en el Periodo Intermedio Temprano. Estas investigaciones incluyen algunas consideraciones sobre las tecnologías de fabricación utilizadas, pero sin considerar un panorama más amplio sobre las narigueras de distintos colores manufacturadas en ese periodo.

Asimismo, al carecer de información sobre cómo se fabricaban las narigueras en general, y las bimetálicas en particular, decidimos hacer el estudio analítico de algunas narigueras de oro y plata monocolores, de tipologías variadas, y algunas bicolores, pertenecientes a diversas colecciones peruanas que carecen de contextos de procedencia conocidos, pero que por sus características morfológicas e iconográficas corresponden al Periodo Intermedio Temprano.

Decidimos observar las piezas por medio de microscopia óptica para identificar posibles uniones y estado de conservación; además aplicamos análisis químico elemental por medio de fluorescencia de rayos $X$ (FRX) con un equipo portátil para obtener la composición química superficial del objeto. Una de las narigueras bicolores fue trasladada al laboratorio para ser analizada por radiografía X y por espectrometría en energía dispersiva (EDS) en un microscopio electrónico de barrido (SEM) para así obtener más información sobre su proceso de manufactura.

Las 39 narigueras analizadas pertenecen a las culturas Mochica y Vicús, y se encuentran en la Colección Poli, en el Museo Nacional de Arqueología, Antropología e Historia del Perú (MNAAHP), en el Museo del Banco Central de Reserva del Perú (MUCEN) y en el Museo de Oro del Perú y Armas del Mundo (MOP).

Los resultados obtenidos para las narigueras de diversas tipologías sean de un color o de dos colores (en particular los porcentajes de plata, oro y cobre contenidos en las aleaciones), fueron comparados, lo que nos permitió deducir algunas de las técnicas utilizadas en su confección, como los tipos de unión que fueron usados para las narigueras bimetálicas. 


\section{1. ¿QUÉ PROPÓSITO TENÍAN LAS NARIGUERAS?}

Las narigueras eran sujetadas en las fosas nasales de tal forma que cubrían parte de la boca, dependiendo de su tamaño. En el Periodo Intermedio Temprano se usaban colocando en las fosas nasales los extremos puntiagudos de la parte central, y durante el Periodo Intermedio Tardío (900-1450 d. C.) se ajustaban por medio de clips o sujetadores (fig. 1).

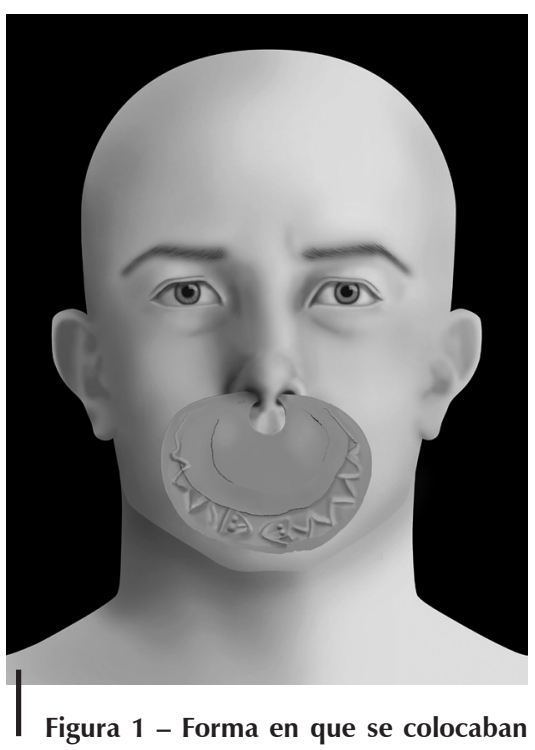

las narigueras en las fosas nasales

Dibujo: M. Rodríguez

Algunos investigadores ofrecen aproximaciones a lo que habría sido el uso de la nariguera y su importancia en estas sociedades, como Jiménez Borja, quien afirma que: «Cicatrices, perforación del septum de la nariz para instalar ahí una nariguera o perforación del labio inferior para un tembetá, pueden ser ornamentos. Las fosas nasales y la boca son aberturas importantes de la cara, por donde pueden penetrar malos espíritus, aires letales. Así pues, no serían adornos sino ornamentos protectores» (Jiménez Borja, 1998: 38).

Otro investigador que se encuentra en esa línea es Karsten (citado por Montell, 1929), quien indica que los indios primitivos acostumbraban perforar el cartílago o la nariz para la inserción de algún objeto, costumbre que tendría un significado puramente mágico. Así, el objetivo principal de los ornamentos de la nariz sería asustar a los espíritus malignos (Montell, 1929: 73).

El cronista Cieza de León menciona el uso de la nariguera por la élite:

Las mugeres andan vestidas como digo: traen los cabellos muy peynados, y en los cuellos muy lindos collares de pieças ricas de oro, y en las orejas sus çarçillos: las ventanas de las narizes se abren para poner vnas como peloticas de oro fino: algunas destas son pequeñas y otras mayores. Tenian muchos vasos de oro los señores, con que beuían, y mantas, assí para ellos como para sus mugeres chapadas de vnas pieças de oro hechas a manera redonda, y otras como estrelletas, y otras joyas de muchas maneras tenían deste metal (Cieza de León, 1984, cap. XVI: 66).

Por su parte, Garcilaso de la Vega dice:

[...] Huaina Cápac passó delante de Quitu y llego a otra provincia llamada Quillacenca: quiere decir nariz de hierro, porque se horadaban la ternilla que hay entre las ventanas de las narizes, y traían colgando sobre los labios un joyelito de cobre o de oro o de plata, como un çarcillo [...] (Garcilaso de la Vega, 1985 [1609], lib. VIII, cap. VII: 338). 
Por último, Guaman Poma de Ayala indica que:

[...] los Guancabilcas también traen zarcillos de oro y les cuelgan de las narices y de las barbas, todo de oro y no son Ingas sino que así se llaman (Guaman Poma de Ayala, 1993, tomo I, folio 85: 70).

Estas tres descripciones sobre el uso de la nariguera son interesantes porque provienen de los cronistas tempranos, quienes obtuvieron la información de primera mano. Cieza de León menciona a las mujeres que portan este tipo de objeto, el metal utilizado y los diferentes tamaños de los mismos; también describe cómo se colocaban en las fosas nasales. Por otro lado, Garcilaso de la Vega y Guamán Poma de Ayala señalan que se utilizó en la zona norte durante la época inca, indicando que tanto en la sierra como en la costa del Ecuador habría evidencia de su uso. Hay que destacar sin embargo que estos cronistas señalan que las narigueras eran decorativas, a diferencia de las interpretaciones dadas por autores contemporáneos y mencionadas líneas arriba.

Una interpretación que proponemos (aunque aún estamos revisándola) para explicar el uso de las narigueras es que la élite trató de «destruir» el cuerpo humano del individuo que fallecía para construir uno divino, transformándose de humano en deidad. Así la nariguera forma parte de la parafernalia de trasformación del cuerpo humano en divino, permitiendo además que cuando hablase el personaje portador de dicho objeto no se le viese gesticular, sino simplemente se escuchaba su voz, haciendo de éste un momento mágico-religioso para el común de la población.

Entre las evidencias que apoyan esta hipótesis se cuentan con escenas de iconografía mochica representadas en las botellas de línea fina, como en un ceramio de estilo Moche IV con la representación de la Ceremonia de Sacrificio, en la que la ejecución de los prisioneros se realiza en la parte alta de la pirámide, bebiendo luego los ejecutantes la sangre de los sacrificados. Los cuatro personajes principales fueron nombrados con las letras A, B, C y D, siendo A el Sol, B la tierra, C el mar y $\mathrm{D}$ la Luna, presentando así la división del poder como una diarquía, típica del pensamiento dual andino. En décadas recientes las excavaciones de diversas tumbas mochica han permitido identificar a estos personajes. En ese contexto, A corresponde al Señor de Sipán, B al Sacerdote Búho, C a la Sacerdotisa de San José de Moro y D a la Señora de Cao (fig. 2) (Alva, 2012; Franco, 2012).

En esta escena se observa a los cuatro personajes principales luciendo narigueras, mientras que los sacrificados no portan este tipo de objeto (Donnan \& McClelland, 1999: 131). En otras botellas o ceramios mochica de línea fina se puede identificar guerreros portando narigueras; pasa lo mismo en la escena de la Rebelión de los Objetos donde observamos pallares vestidos de guerreros portando estos objetos nasales. Es interesante que las narigueras van cambiando de forma entre semilunar, casi ovaladas, o rectangulares, en tanto que algunas tienen colgantes circulares (Donnan \& McClelland, 1999: 181, 247). Asimismo, notamos narigueras bicolores que son exhibidas por varios personajes de élite. No es posible asignar un color a una forma determinada ya que en una sola escena donde los guerreros están caminando en fila se observa que cada uno porta una nariguera distinta en forma 


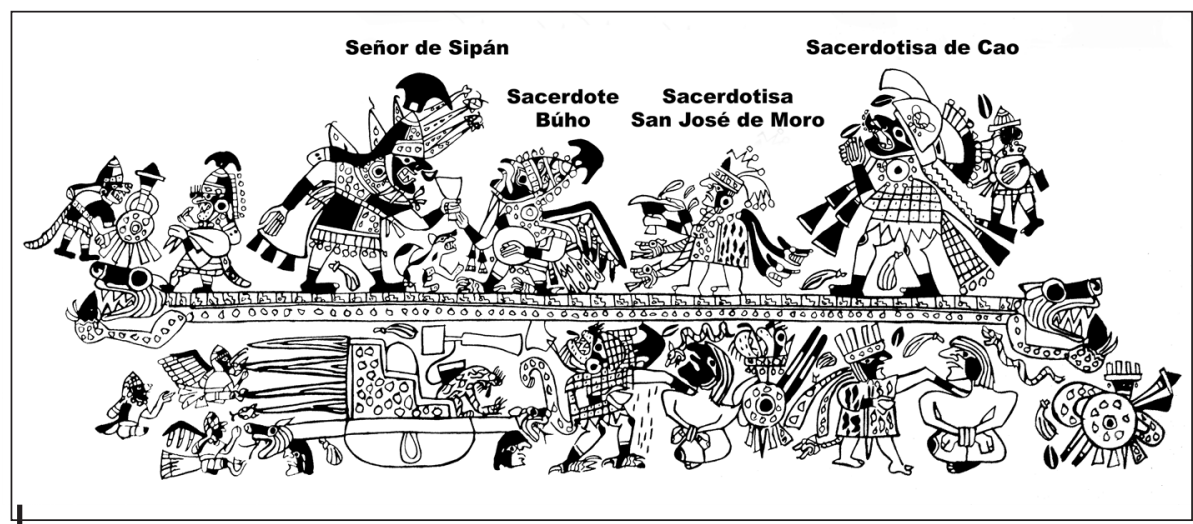

Figura 2 - Escena de la Ceremonia de Sacrificio, Moche IV

Tomado de Donnan \& McClelland, 1999: 131

y color; sin embargo, quienes portan las narigueras ovaladas tienen el casco con representaciones de plumas y el escudo cuadrado, mientras que quienes lucen la nariguera rectangular llevan casco con figuras serpenteadas y escudo redondo. Estas concordancias permitirían identificar dos grupos étnicos definidos (fig. 3). Por otro lado, en otra escena en la que aparecen dos guerreros peleando, uno de ellos sería mochica y el otro recuay por el tocado frontal, típico de Recuay, y por las armas que porta como la guaraca, de uso común en la sierra (Donnan \& McClelland, 1999: 266).

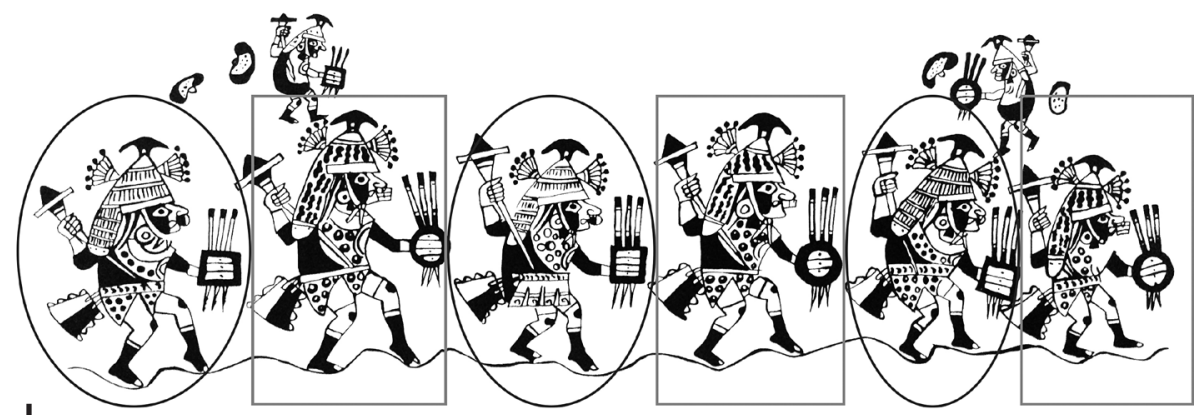

Figura 3 - Escena de guerreros que portan diferentes narigueras (semilunares, ovaladas o rectangulares); además algunas tienen colgantes circulares, Moche IV

Tomado de Donnan \& McClelland, 1999: 227 


\section{LAS NARIGUERAS EN OTRAS CULTURAS AMERICANAS}

Este tipo de objeto no fue usado solo en el área andina, sino también en otras partes de América. Por ello, para aproximarnos a su significado, revisaremos las evidencias de algunas de las zonas en las que se utilizaron las narigueras.

En Colombia, los uwa (tunebos) de habla chibcha, ubicados en la cordillera nororiental de Colombia, usaron narigueras de oro hasta épocas recientes. La religiosa María de Betania (1964: 82, citada por Falchetti, 1997) registró su uso entre individuos de un clan no especificado. Eran usadas comúnmente solo por hombres y mujeres jóvenes cuando pretendían casarse. Para muchas comunidades, la nariguera de metal, junto con otros elementos, ha sido símbolo importante del papel social de la mujer y también en las alianzas matrimoniales y en el intercambio. No sorprende encontrar el uso de narigueras de oro entre los uwa, si el metal se asociaba con la «semilla femenina embriónica», y era relacionado con el mito de las abejas, en donde la miel y la cera se identifican como sinónimos de semilla, germinación y fertilidad. Asimismo, el oro está asociado a todas las características divinas de fertilidad (Falchetti, 1997).

En su interesante tesis «El gesto animal y el objeto humano: Construcción de narrativas y prácticas corporales en las narigueras yotoco, malagana y sonso», sobre sociedades agroalfareras (1500 a. C.-600 d. C.) del valle del Cauca en Colombia, Parra menciona la importancia de la capacidad de transformación de la apariencia del individuo como elemento clave para la construcción de la identidad. Esta última se define en dos campos: como personaje en la sociedad y en la interpretación de alguna performance. Asimismo, menciona que la nariguera es una pieza adaptada al cuerpo del individuo. La funcionalidad del objeto y su adaptación al rostro tienen importancia al momento de la elección del tamaño, diseño, forma, decoración, brillo, sonido, portabilidad y peso, si se desea utilizar las narigueras como pinzas, en forma semilunar, atravesando el septum nasal, entre otras. Así Parra menciona que:

[...] diademas, pectorales, narigueras, brazaletes, colgantes, adornos para las orejas, los labios, la quijada o los órganos sexuales transformaban no solo la apariencia de quien los portaba, sino que construían un individuo (Parra Benavides, 2016: 33).

Por otro lado, también para Colombia, Pinedo menciona la transformación del cuerpo con relación en una puesta en escena, actividad o acción de orden que difiere de los días ordinarios, donde no se considera al atuendo como un conjunto de objetos de adorno personal, sino como una «segunda piel que transforma el cuerpo físico en un cuerpo sagrado». Así Pinedo indica que:

[...] los miembros de las sociedades indígenas asumen diversas identidades a lo largo de su vida. Durante el curso de su historia personal, tienen y transmiten variados nombres, participan en ritos de paso y otras ceremonias, y se sirven de pinturas, tatuajes y otros adornos corporales para marcar sus propias identidades, construyendo de esta forma su propio cuerpo. 
Las pinturas, los adornos, los tatuajes y otras formas de modificación del cuerpo son una especie de segunda piel, sin la cual no es concebible la naturaleza humana. Nuestra segunda piel es a la vez la expresión y puente de la vida social, vía de acceso a nuestra participación en la vida ritual y ceremonial (Pineda Camacho, 2005: 26).

Sáenz Samper (1993) estudia los grupos sociales zenú de la zona oriental de Colombia e indica que en los ajuares funerarios sobresalen adornos orfebres como pectorales semilunares, narigueras, orejeras, collares, remates de bastón, colgantes, entre otros. Además, resalta la importancia de todas las piezas hechas en oro, sobre todo las narigueras, compuestas de variados diseños y aplicaciones, porque reforzaban el poder y el prestigio de los personajes que las usaban, sobre todo de las mujeres, derivado de su uso.

Por otro lado, Vela indica que en Mesoamérica el uso de narigueras estaba reservado a los miembros de la élite, así como a personajes de alto rango. Elaboradas con materiales preciosos, eran objetos principales de la vida ritual. Así Vela afirma que:

[...] los simbolismos específicos que se les atribuían [a los objetos elaborados de materiales preciosos], se asociaban a determinados dioses, fiestas y ritos. Es por ello que en ciertas ocasiones los participantes del ritual debían portar elementos que los asociaran con alguna divinidad. Si bien existía la clase de adornos que eran de uso general, había los que estaban reservados por la posición social o por méritos. En estas situaciones se realizaban ceremonias específicas durante las cuales se les entregaban por ejemplo bezotes y narigueras, y cuando era el caso se hacían las modificaciones corporales necesarias para que los portaran (Vela, 2015: 20).

Este investigador indica también que desde el Periodo Clásico (200-900 d. C.) los ritos de investidura de los gobernantes de grupos como los mixtecas incluían la perforación de la nariz para colocar la nariguera, acción que los confirmaba como gobernantes y fundadores de linaje. En el caso de los mexicas, Vela señala que algunos militares accedían al uso de las narigueras debido a su buen desempeño en las campañas bélicas. Por otro lado, menciona que es posible que estas narigueras simbolizaran el aliento vital de quien las portaba. Por último, las narigueras tenían significados específicos según su forma; por ejemplo, las de mariposa se relacionan con Xochipilli-Macuilxóchitl, las de greca escalonada cuyos extremos rematan en rayos se relacionan con el Sol, en tanto que algunas de ellas eran parte de los atributos que distinguían a algunos dioses, como el caso de las narigueras de forma semilunar que eran asociadas a los dioses del pulque (Vela, 2015: 46).

Benítez Turrubiates también sostiene que las narigueras de mariposa se asociaban con Xochipilli-Macuilxóchitl, el dios patrono de la llegada del cambio de la naturaleza, las flores, los pájaros, las mariposas, y también del canto, la danza y la música. Menciona además que se conocen narigueras de mariposa estilizada que proceden principalmente de la región oaxaqueña. Igualmente refiere que las narigueras colgantes que asemejan la greca escalonada y rematan con rayos luminosos tenían un simbolismo relacionado con el Sol. Los nobles y los grandes señores de la sociedad mexicana las lucían durante las fiestas religiosas (Benítez Turrubiates, 2017). 
En su estudio sobre mesoamericanos en la Bahía de Culebra, al noroeste de Costa Rica, Solís Del Vecchio y Herrera Villalobos mencionan que en el sitio Jícaro se reconocen grupos sociales con características similares (tanto físicas como sociales) a aquellas de los inmigrantes mesoamericanos, y que fueran citadas en fuentes del siglo XVI. Por ejemplo, se observa en contextos domésticos y funerarios una fuerte presencia de figurillas femeninas asociadas a restos óseos de mujeres adornadas con orejeras y narigueras (Solís Del Vecchio \& Herrera Villalobos, 2011). Los investigadores añaden que:

[...]precisamente, uno de los individuos con más elementos suntuarios, entre los que están una nariguera y un brazalete hecho con cuentas de piedra verde, concha, resina, perla y oro, era una mujer con deformación craneal y limadura dental (Solís Del Vecchio \& Herrera Villalobos, 2011: 19).

Las características del uso de la nariguera en diferentes culturas precolombinas desde Mesoamérica, pasando por Colombia, Ecuador y Perú, revelan que estos objetos cumplieron un papel importante en la construcción de la identidad del personaje que la portaba.

\section{LAS NARIGUERAS COMO SÍMBOLO DE PRESTIGIO Y PODER EN LAS CULTURAS PRECOLOMBINAS PERUANAS}

En las culturas precolombinas peruanas, desde Chavín hasta la de los incas, las élites se ataviaban con una gran parafernalia metálica que consistía en coronas, orejeras, narigueras, pectorales, plumas, láminas de metal cosidas a las vestimentas, entre otros. Estos objetos no solo fueron usados en vida por estos individuos durante las ceremonias rituales, también fueron enterrados con ellos. Las crónicas mencionan que las piezas metálicas de oro y plata que portaban los gobernantes deslumbraban al pueblo, ya que sus colores — vinculados a los del Sol y la Luna, divinidades veneradas en tiempos prehispánicos-, brillo y diversos sonidos hacían que los gobernantes parecieran seres sobrenaturales. Murúa ofrece un ejemplo del deslumbramiento que podían producir el oro y la plata cuando relata cómo «Manco Capac armó caballero a su hijo Sinchiroca y entró por fuerza en el Cuzco y se enseñoreó dél»:

Otros ponen la entrada deste valeroso Manco Capac en el Cuzco de diferente manera y traza, diciendo que habiendo venido con sus hermanos, hijo y mujer, hizo estirar dos planchas de oro muy delgadas, y poniéndose una en los pechos y otra en las espaldas y una diadema, que los indios llaman canipo, en la cabeza, envió al Cuzco a un yndio diciendo que era hijo del sol, y que le recibiesen y obedeciesen por tal y por señor della, y que para que ellos lo viesen se mostraría en un cerro alto, donde salió y fue visto de los indios poques naturales del Cuzco en la cumbre del cerro pasearse, y como los rayos del sol hiriesen en las planchas y diadema, resplandecieron y daban de sí gran luz y claridad, y viéndolo los indios, atemorizados, lo 
tuvieron por hijo del sol y cosa divina y así le obedecieron y recibieron por señor absoluto, dándole la obediencia y ofreciéndole innumerables riquezas y tesoros y todo cuanto quiso, con lo cual se hizo rico y poderoso, y salió después a conquistar algunos pueblos cercanos que no le obedecían (Murúa, 2001: libro I, cap. III: 46).

La nariguera es uno de los objetos que la élite gobernante lució en el área andina de manera característica desde muy temprano (Onuki, 1997). Ella se colocaba en las fosas nasales, cubriendo la boca, y su uso estuvo muy difundido entre las poblaciones del Periodo Intermedio Temprano (200 a. C.-600 d. C.) y Periodo Intermedio Tardío (900-1375 d. C.), aunque Onuki halló narigueras como parte de las ofrendas funerarias de los individuos excavados en Kuntur Wasi, sitio característico del Horizonte Temprano (Onuki, 1997). Además, en el norte del territorio andino, los mochica, frías y vicús, poblaciones del Periodo Intermedio Temprano, así como los sicán y chimú del Periodo Intermedio Tardío, elaboraron una amplia gama de estos objetos que podemos apreciar en varios museos y colecciones públicas y privadas, así como en las excavaciones arqueológicas que se realizan en el Perú desde la década de 1980.

Por ejemplo, las excavaciones que Walter Alva realiza desde 1987 en el sitio de Huaca Rajada, en la región de Lambayeque en la costa norte, han revelado tumbas de élite en las que se puede apreciar la gran parafernalia metálica que acompañaba a cada uno de estos individuos de gran prestigio. Entre estos objetos metálicos se encuentran abundantes narigueras. Entre aquellas que acompañaban al Señor de Sipán destacan dos de forma semilunar, confeccionadas en oro y encontradas a la altura del mentón, así como otras dos, una de oro y otra de plata, de forma convexa, encontradas cerca del cráneo. Asimismo, encontramos narigueras como parte de la parafernalia metálica que lucían los personajes que se representaban en los distintos objetos que acompañaban a este importante individuo. Tal es el caso de las orejeras, donde el personaje principal —que representaría al Señor de Sipán- porta una nariguera semilunar; asimismo los personajes que se encuentran representados en los cuatro estandartes lucen una nariguera 'dorada' circular con semicírculos embutidos en todo el borde. Así también, en la tumba del Viejo Señor no solo se observan narigueras de oro de forma semilunar, sino también de oro y plata de forma rectangular, una de ellas con la representación de un personaje antropomorfo que luce una nariguera de oro de forma semilunar. En general, los ajuares funerarios de los personajes de élite excavados por Alva en Huaca Rajada incluyen narigueras de oro, plata y tumbaga, al igual que los personajes antropomorfos representados en distintos soportes como orejeras y estandartes, entre otros (Alva, 2015). Esto nos permite entender la importancia de estos objetos dentro del ajuar funerario, así como conocer las distintas formas en las que se elaboraban.

Al igual que en el caso de Huaca Rajada, en el sitio mochica de Dos Cabezas ubicado en Jequetepeque, región La Libertad, en la costa norte del Perú, tres de las cinco tumbas excavadas por Donnan contenían personajes principales acompañados de una gran cantidad de objetos de metal, entre los cuales la nariguera es un elemento recurrente. Ellas se confeccionaron en oro, plata y 
cobre, pero también pueden ser bimetálicas; tienen forma semilunar o circular con semicírculos embutidos, y las lucen también las figuras antropomorfas representadas en distintos soportes (Donnan, 2007).

De la región Piura proviene un gran número de narigueras elaboradas en formas diversas y con distintos metales. De las tumbas moche excavadas ilícitamente en el sitio de Loma Negra, en Vicús, se recuperaron varios ejemplares de narigueras bimetálicas con una rica iconografía (Schorsch, 1998; Schorsch et al., 1996). Así también, en el sitio de Frías, en la sierra de Ayabaca, se realizaron excavaciones ilícitas de las que se recuperó una gran cantidad de narigueras del Periodo Intermedio Temprano, elaboradas en oro y aleación de oro y plata (Carcedo et al., 2013; Vetter, 2017).

También en Piura, Guzmán y Casafranca excavaron en 1964 varias tumbas en el sitio vicús de Yécala, a unos 6,5 kilómetros del cerro Vicús en la costa peruana. El individuo principal tenía dos narigueras de oro ovaladas con decoración de semicírculos embutidos (Guzmán Ladrón de Guevara \& Casafranca, 1964). Estos especímenes fueron estudiados por Ríos \& Retamoso (1993) y descritos por Castillo Narrea \& Fernández (2017). Otras narigueras saqueadas en las décadas de 1950 y 1960 en el área de Vicús se encuentran actualmente en la colección del Museo del Banco Central de Reserva (Vetter, 2014).

Shimada excavó tumbas de élite sicán del Periodo Intermedio Tardío de la costa norte y reportó el hallazgo de menor cantidad de narigueras. Sin embargo, el personaje principal, o la máscara que lo acompaña, luce siempre una nariguera que, en vez de las dos puntas que se prendían en la ternilla en periodos anteriores, tiene ahora dos ganchos en forma de clips o sujetador que van prendidos de ella (Shimada, 1995: 79, fig. 61).

Las narigueras sicán se confeccionaron sobre todo en oro, aunque aquellas de las máscaras son de cobre con oro. Los chimú las elaboraron principalmente en plata, de gran tamaño y con representaciones de escenas caladas, como se muestran en la colección del Museo Arqueológico Rafael Larco Herrera en Lima.

A pesar de que en los últimos tiempos las investigaciones arqueológicas permiten tener mayor conocimiento sobre las narigueras en cuanto a las formas, además de distintas interpretaciones sobre su uso y función, no hay estudios precisos sobre su manufactura y producción. Debido a esta falta de información sobre la tecnología aplicada en la manufactura de las narigueras se decidió analizar 39 narigueras procedentes de colecciones privadas y estatales, para poder reconstruir el proceso de elaboración de las mismas.

\section{TECNOLOGÍAS EMPLEADAS EN LA ELABORACIÓN DE LAS NARIGUERAS PRECOLOMBINAS PERUANAS}

Las narigueras precolombinas peruanas tienen formas y tamaños muy variables. Desde muy simples a muy complejas, las piezas fueron elaboradas en aleación de oro (incluso tumbaga), en aleación de plata o con ambos metales. Con excepción 
de lo que es posible deducir a partir de una observación detallada de las piezas, y de lo que fue publicado sobre narigueras procedentes de raros contextos específicos (por ejemplo, Schorch, 1998; Hörz \& Kallfass, 1998; Notis et al., 2005; Cesareo et al., 2016; 2017) no se sabe de manera general qué tecnologías se emplearon para confeccionarlas, incluso para lograr los colores de las narigueras bicolores.

Algunas narigueras son efectivamente de manufactura muy simple. Fueron meramente cortadas en una lámina metálica y después decoradas por repujado con motivos más o menos complejos, pero generalmente simétricos. En las figuras $4 \mathrm{a}$, 4b y 4c se muestran ejemplares de la costa norte peruana que fueron confeccionados de esa forma. Ese tipo de nariguera también predomina en otras culturas, como las que se desarrollaron en el territorio actual de Colombia (Plazas de Nieto \& Falchetti, 1978; Plazas de Nieto, 1998), donde pueden tener gran tamaño (Plazas, 2007; Bray, 2003) y fueron elaboradas en oro o tumbaga dorada por enriquecimiento (Sáenz-Samper \& Martinón-Torres, 2017).

Otras narigueras presentes en colecciones peruanas, confeccionadas de forma idéntica a las anteriores pero a veces decoradas con motivos complejos, tienen franjas en superficie de un color que actualmente se ve marrón-negruzco. En la figura 5 se muestra un ejemplar de este tipo. Este trabajo de orfebre evoca los discos rotatorios de la cultura Piartal-Tuza (Nariño Tardío, 600-1700 d. C.) que se desarrolló en Colombia. Esos discos, en tumbaga bruñida, fueron atacados con ácido para formar el motivo geométrico (Plazas de Nieto, 1977-1978).
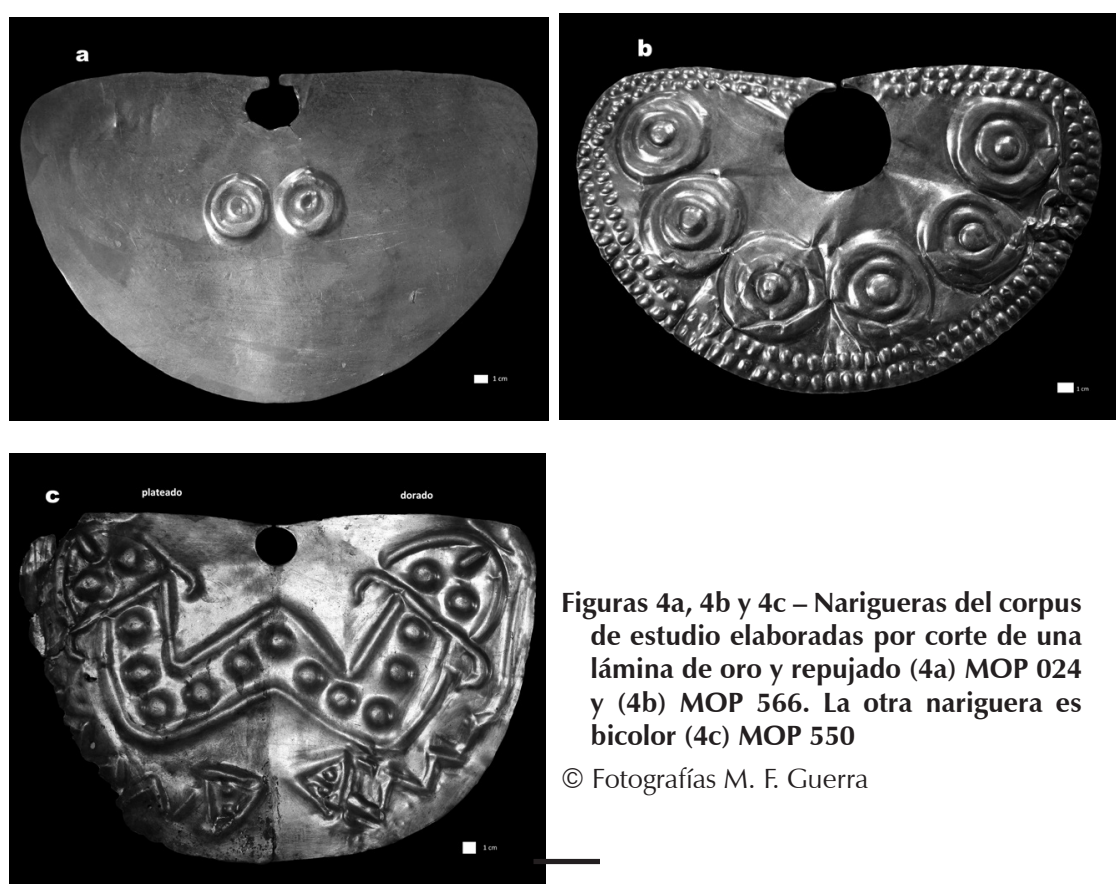

Figuras $4 a, 4 b$ y $4 c-$ Narigueras del corpus de estudio elaboradas por corte de una lámina de oro y repujado (4a) MOP 024 y (4b) MOP 566. La otra nariguera es bicolor (4c) MOP 550

C) Fotografías M. F. Guerra 


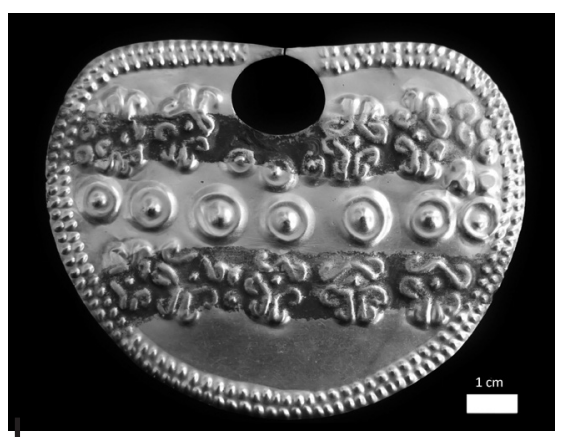

Figura 5 - Nariguera del corpus de estudio Poli 13 elaborada en lámina de oro y decorada por repujado y con dos franjas de color marrón-negruzco

(C) Fotografía L. Vetter

Otras narigueras peruanas, también elaboradas por simples corte de la lámina y a veces decoradas por repujado, son bicolores, sin que a simple vista se pueda deducir la tecnología empleada para obtener la bicromía (fig. 4c). Se supone, en general, que los objetos son de oro y plata, como varias producciones suntuarias del periodo Sicán Tardío y del periodo Chimú (Carcedo, 2017), siendo todavía posible emplear varios métodos para obtener los dos colores, como por ejemplo en las 41 narigueras bimetálicas y otros objetos encontrados en la tumba de la Señora de Cao (Cesareo et al., 2016; 2017) o los objetos bimetálicos de la tumba del Señor de Sipán (Hörz \& Kallfass, 1998). En el caso de las piezas de la tumba de la Señora de Cao, los autores interpretan sus resultados indicando que las uniones de las partes blancas de plata y amarillas de oro se lograban empleando resinas naturales como pegamento, por soldadura y también por amalgamación de mercurio. En el caso de las piezas de la tumba del Señor de Sipán, los autores afirman que las técnicas empleadas para unir partes de distintos colores en oro, plata y cobre fueron la soldadura blanda y fuerte.

Algunas narigueras se confeccionaron con técnicas más complejas, pues la lámina principal, que puede ser plana o curva para que el objeto sea tridimensional, fue decorada añadiendo elementos metálicos. Estos últimos (hilos, gránulos y láminas) se soldaban a la lámina principal (Notis et al., 2005) para formar varios motivos, como se muestra en las figuras $6 \mathrm{a}, 6 \mathrm{~b}$ y $6 \mathrm{c}$. Este tipo de nariguera se encuentra también en uno y dos colores.

\section{NARIGUERAS DE LAS CULTURAS PRECOLOMBINAS PERUANAS: EL CORPUS DE ESTUDIO Y MÉTODOS EMPLEADOS}

En este primer análisis tecnológico de las narigueras nos concentramos en la producción de la costa norte peruana, eligiendo piezas bidimensionales sin elementos de decoración añadidos. Todas las piezas pertenecen a las culturas Mochica y Vicús, del Periodo Intermedio Temprano. En total se analizaron 39 narigueras (cuadro 1): 5 pertenecen a la Colección Poli, 5 a la colección del Museo Nacional de Arqueología, Antropología e Historia del Perú (MNAAHP), 10 a la colección del Museo del Banco Central de Reserva del Perú (MUCEN) y 19 al Museo de Oro del Perú y Armas del Mundo (MOP). De las 39 piezas analizadas, 23 son bimetálicas y 16 son de oro. 
Cuadro 1 - Las narigueras que forman parte de esta investigación

Se indican la colección a la que cada una pertenece, los estilos atribuidos y la composicion de las partes en oro (Au-oro, Ag-plata, Cu-cobre, en \%)

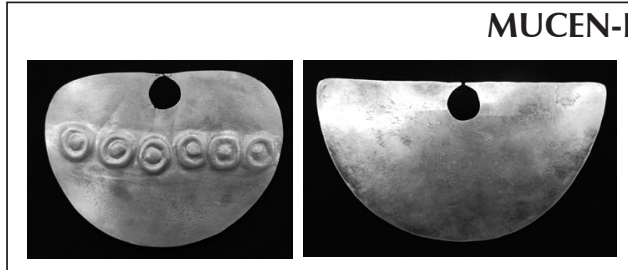

MUCEN BCRP AAU 2014 MUCEN BCRP AAU 1896 Vicús, Colección Seminario Au80 Ag16 Cu4
Vicús/Moche, Colección Seminario Au75 Ag20 Cu4

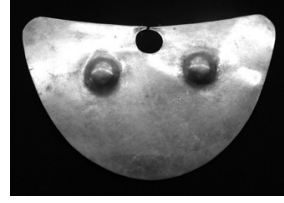

MUCEN BCRP AAU $1977 \mathrm{a}$

Vicús, Colección Seminario

Au74 Ag23 Cu3

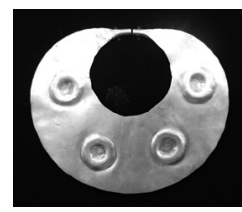

MUCEN BCRP AAU 2068

Vicús, Colección Seminario Au81 Ag17 Cu2

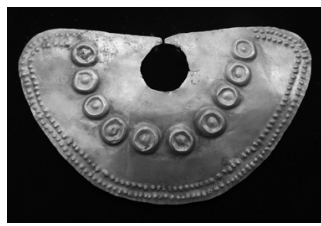

MUCEN BCRP AAU 1948 Vicús, Colección Seminario Au82 Ag15 Cu3

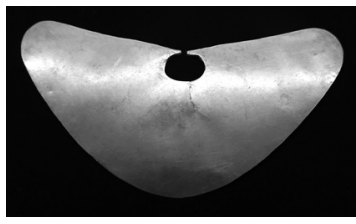

MUCEN BCRP AAU 1894 Vicús/Moche, Colección Seminario Au82 Ag16 Cu2

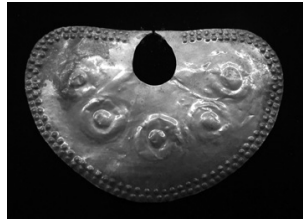

MUCEN BCRP AAU 1977b

Vicús, Colección Seminario Au74 Ag23 Cu3

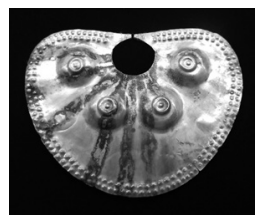

MUCEN BCRP AAU 2052

Vicús, Colección Seminario.

Au84 Ag14 Cu2

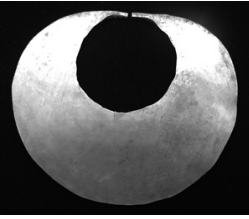

MUCEN BCRP AAU 1907

Vicús/Moche, Colección Seminario Au85 Ag13 Cu2

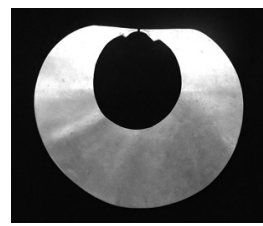

MUCEN BCRP AAU 2034,

Vicús, Colección

Seminario.

Au78 Ag20 Cu2

\section{Colección Poli}

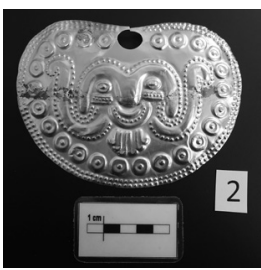

Poli 2, Vicús Au84 Ag14 Cu2

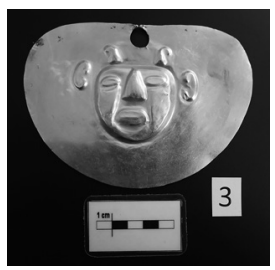

Poli 3, Intermedio Temprano Au80 Ag20 Cu1

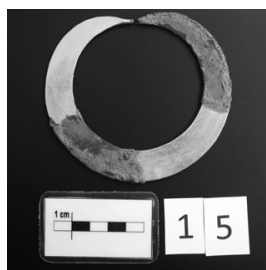

Poli 15, Moche Au86 Ag13 Cu1 


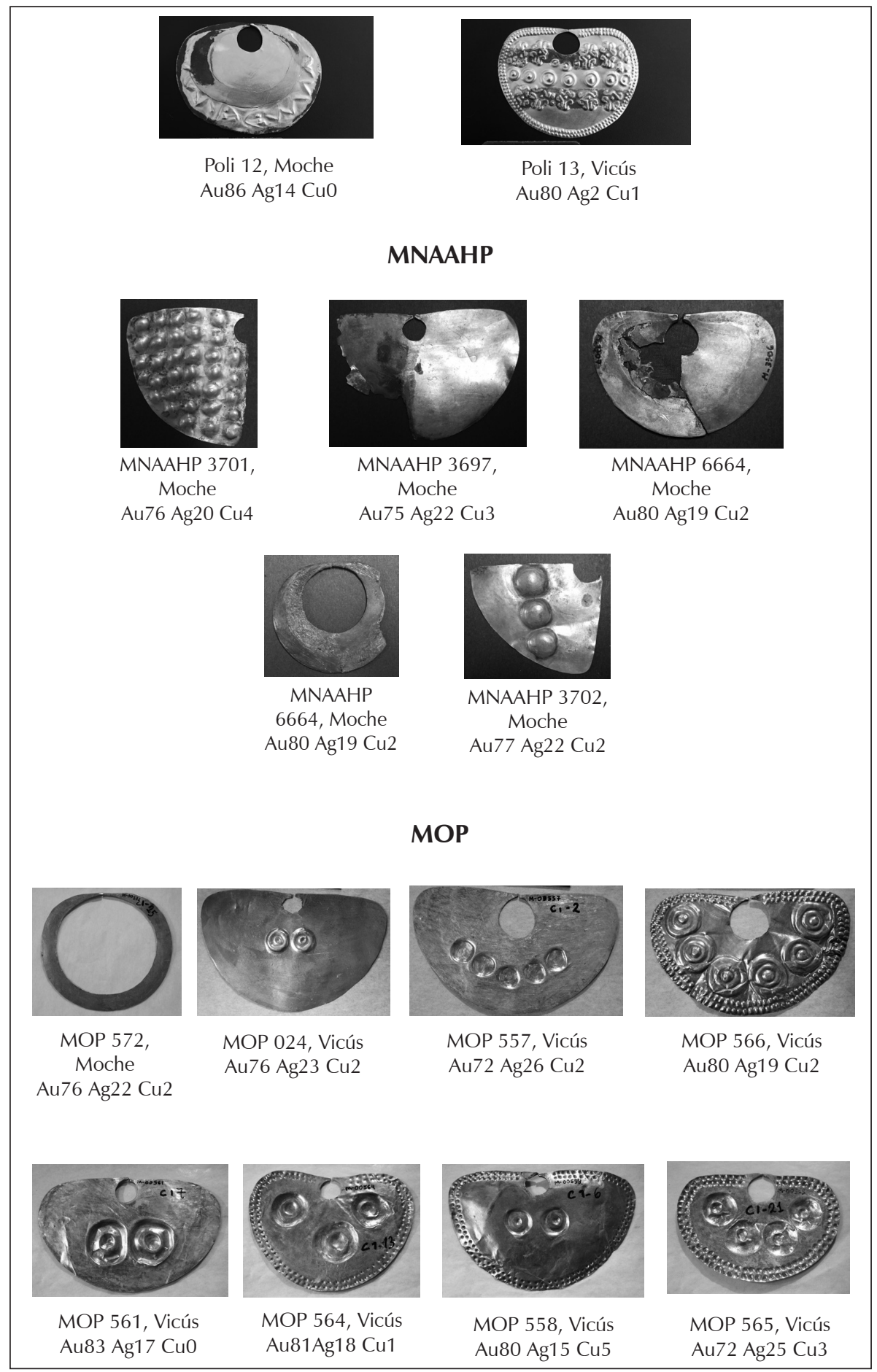




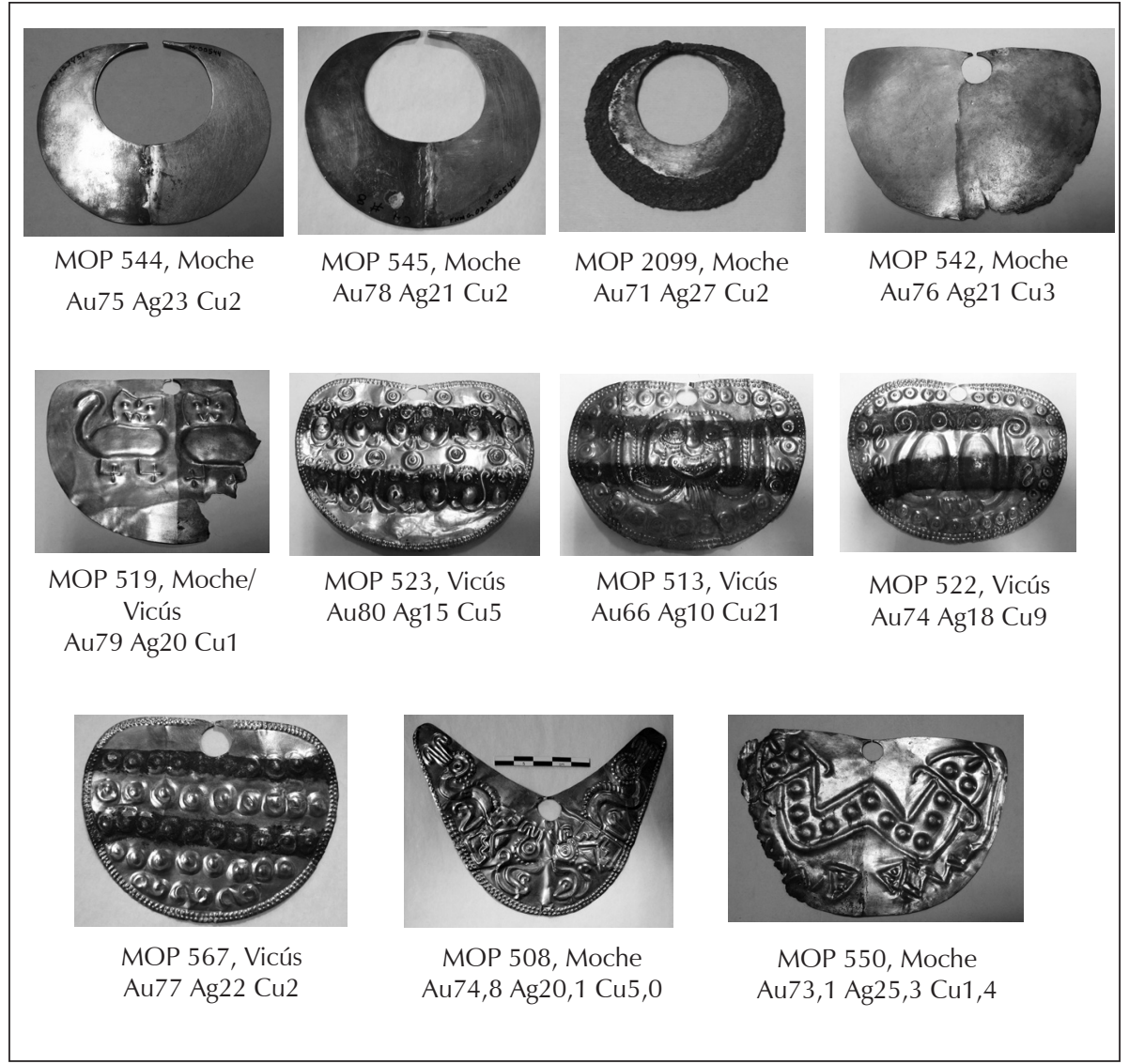

(C) Fotografías M. F. Guerra y L. Vetter
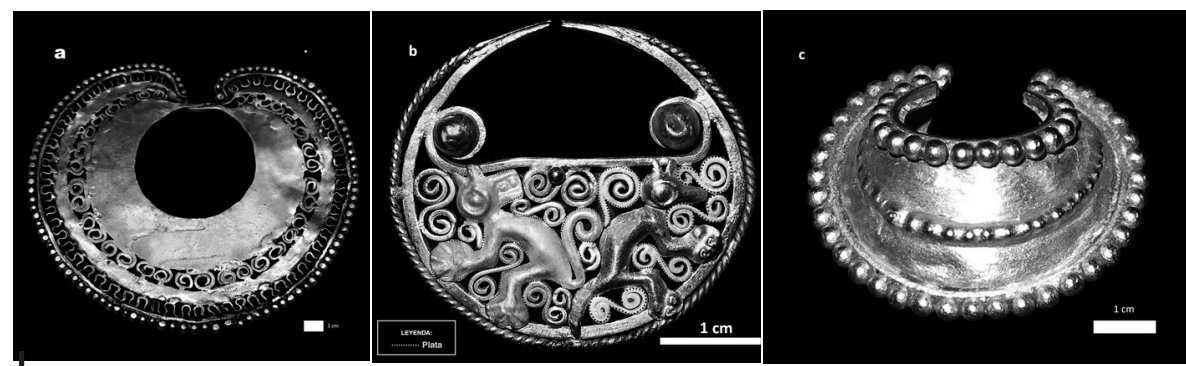

Figuras 6a, 6b y 6c - Narigueras del corpus de estudio decoradas con motivos elaborados por unión de 6a) hilos y gránulos (MNAAHP 3123); 6b) hilos, gránulos y lámina de dos colores, -en la fotografía lo punteado es el color plateado- (Poli 6); 6c) gránulos a una lámina curvada para crear un efecto de tridimensionalidad (Poli 25)

(C) Fotografías M. F. Guerra y L. Vetter 
Las narigueras fueron observadas macroscópicamente para determinar formas y estilos, y separadas en tres grupos de acuerdo a su forma e iconografía: estilo Mochica, estilo Vicús y estilo Mochica/Vicús. Debido a que no provienen de excavaciones arqueológicas, es difícil asignarles con seguridad una procedencia cultural, por lo que recurrimos al «estilo» para ubicarlas tempo-espacialmente.

Luego todas las piezas fueron observadas detalladamente por medio de microscopia óptica para verificar detalles de la elaboración. Una de las narigueras bicolores fue estudiada por radiografía digital con un equipo de Digital Radiography Equipment, fabricante VIDISCO, modelo RAYZOR X, con fuente de rayos X General Engineering 270 kV constante. Para determinar las aleaciones utilizadas en la elaboración de las narigueras, las piezas fueran analizadas por medio de fluorescencia de rayos X (FRX) con un equipo portátil de Niton, Thermo Scientific, de la serie XL3t GOLDD, operado en modo Metales Preciosos y con tiempos de adquisición entre 120 s y 300 s. Una de las narigueras bicolores fue además observada y analizada por medio de espectrometría de rayos $\mathrm{X}$ por dispersión de energía (EDS) en un microscopio electrónico de barrido (SEM) JEOL JSM-IT300, con un voltaje de aceleración de 20 kV y con cuantificación ZAF.

\section{ELABORACIÓN DE LAS NARIGUERAS}

Todas las narigueras analizadas fueron elaboradas por laminado y corte, siendo los extremos acabados por martillado (fig. 7). Aquellas que tenían decoración revelaron que los motivos fueron ejecutados por repujado.

Las narigueras de un solo color fueron confeccionadas a partir de una lámina de oro. Los resultados obtenidos por FRX y SEM-EDS muestran que sus aleaciones son poco variables, con cantidades de cobre que van de $0,3 \%$ a 2,5 \% y cantidades de plata que varían entre $15 \%$ y $25 \%$, sin distinción de estilo definido encima. Solo una de las narigueras tenía una cantidad de cobre superior (cerca de 5\%), pero su aspecto no muestra evidencias que permitan sospechar que sea tumbaga.

Las narigueras bimetálicas son de dos tipos: las que son mitad plata y mitad oro (fig. 4c) y las que son de oro con franjas al presente de color marrón-negruzco (fig. 5). Algunas de las primeras tienen un aspecto distinto debido únicamente a sus diversos estados de conservación (figs. 8a, 8b y 8c). Contrariamente a las aleaciones de oro, las de plata están muy afectadas por la corrosion atmosférica (Tissot et al., 2016a; 2017). No obstante, el estado de conservación de algunas de las piezas muestra que las partes blancas fueron elaboradas en plata, que se encuentra actualmente mineralizada.

En el caso de las narigueras bimetálicas, algunas de ellas muestran en la región donde los dos colores coexisten una juntura muy visible, de tipo soldadura, que podría ser el resultado de una restauración moderna. En la mayoría de los ejemplares estudiados no existe una unión visible. La región sin unión visible de las narigueras bimetálicas (figs. 9a y 9b) tiene morfología y aspecto idénticos a los de la unión por martillado (hammered-welded, Schorsch, 1998) de una lámina de 
oro a una lámina de plata, como aquella realizada por el orfebre Robert Baines cuando simuló objetos bimetálicos, al igual que las narigueras de Loma Negra (Schorsch, 2014: fig. 12.17c).

Para verificar esa posibilidad, en la figura 10 se presentan las concentraciones de plata (Ag) y oro ( $\mathrm{Au}$ ) obtenidas por FRX 1 para los 2 colores de 9 narigueras bimetálicas. En las otras narigueras -a

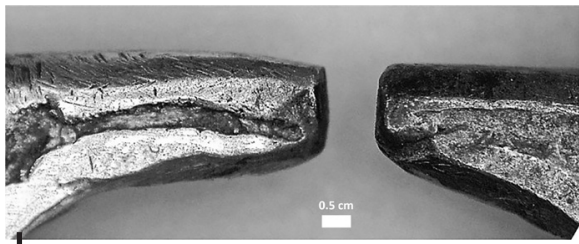

Figura 7 - Acabado por martillado de los extremos de una de las narigueras bimetálicas del corpus de estudio

(C) Imagen M. F. Guerra veces incompletas por corrosión de

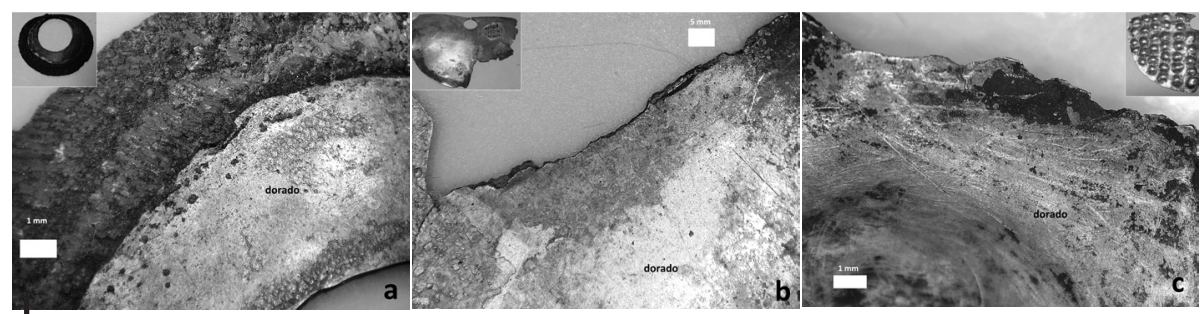

Figuras 8a, 8 b y 8c - Algunas de las narigueras bimetálicas se encuentran en distintos estadios de conservación debido a la mineralización de la plata: (8a) nariguera MOP 2099 muy corroída pero todavía completa; (8b) nariguera MNAAHP 3697 con la parte en plata incompleta; (8c) nariguera MNAAHP 3701 limitada hoy a su parte dorada

(c) Imágenes M. F. Guerra

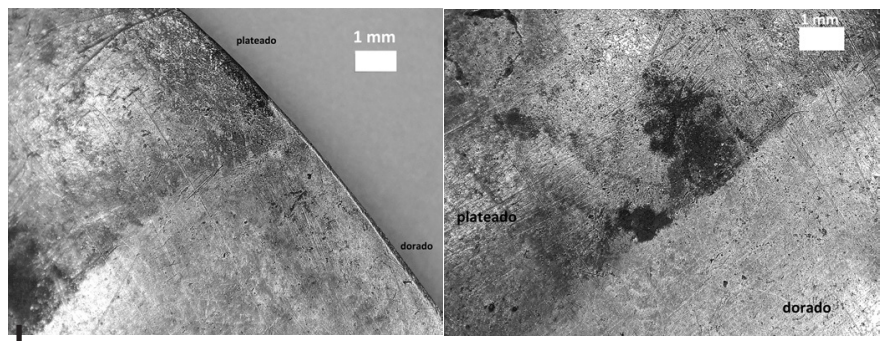

Figuras 9a y 9b - Región de unión de la parte blanca y dorada de la nariguera MOP 519, cuya morfología evoca la unión por martillado (hammered-welded, Schorsch, 2014)

(c) Imágenes M. F. Guerra

la parte en plata - no fue posible analizar con seguridad los dos colores. En la mayoría de piezas se observa una inversión de los valores de Ag y Au, de acuerdo con el color de la región analizada, lo que parece corresponder — como fue sugerido por Robert Baines (Schorsch, 1998; 2014)—a la unión de dos láminas bruñidas, una de oro y otra de plata.

1 Esa composición es la de una capa fina, correspondiendo a los primeros $\mu \mathrm{ms}$ (Guerra, 2008; 2018; Troalen \& Guerra, 2016). 


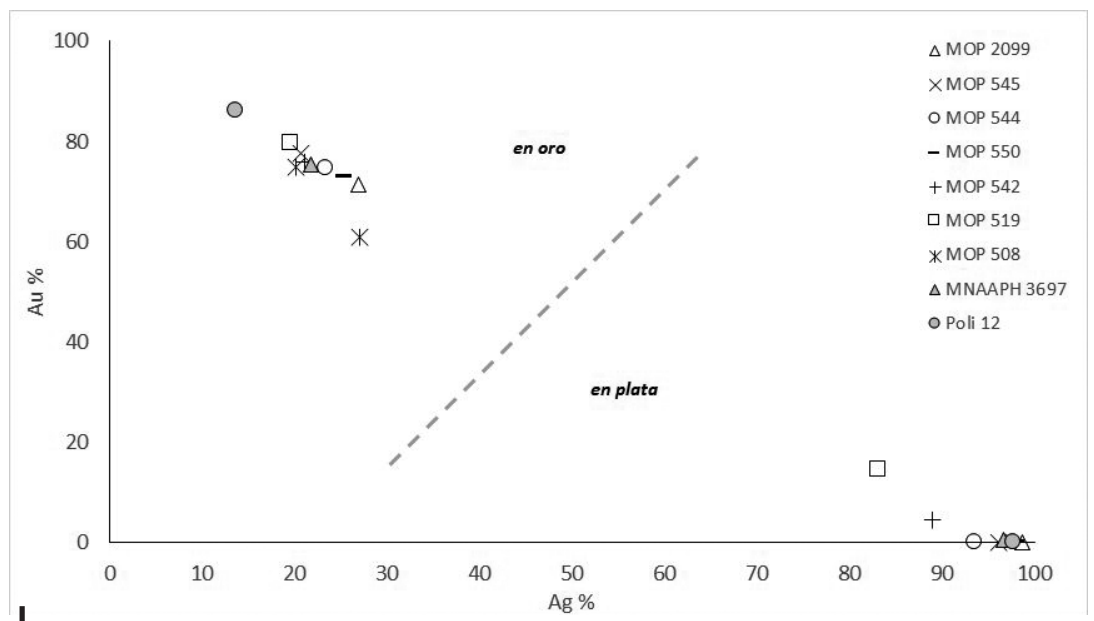

Figura 10 - Valores de plata (Ag) y de oro (Au) obtenidos por FRX para los dos colores de nueve narigueras bimetálicas

Cada par de puntos corresponde a los valores obtenidos para la parte blanca (en plata) y para la parte dorada (en oro) de las narigueras

Elaboración M. F. Guerra

Una de las narigueras, cuya unión es invisible, destaca en el diagrama de la figura 10 por tener casi las mismas cantidades de oro y de plata para los dos colores (indicada MOP 508). Esa nariguera podría haber sido elaborada con la misma técnica, pero con una lámina en una aleación que contiene altos valores de oro y plata. Como es bimetálica en ambas caras se puede considerar la posibilidad de elaboración por dorado por sustitución electroquímica (electrochemical replacement plating), como fue descrito por Lechtman (1979) para los objetos de Loma Negra. Para comprobar esta afirmación se tendría que realizar otros estudios de la superficie de la pieza, lo que obligaría a moverla de su contexto de conservación hasta el laboratorio.

Por otro lado, la observación detallada por microscopia óptica de las narigueras en oro con franjas de color marrón-negruzco muestra que las zonas coloridas están cubiertas actualmente de un compuesto granuloso cuya morfología evoca productos de corrosión (fig. 11a). Se debe todavía considerar que la morfología de los productos formados por corrosión artificial (patination) y natural de aleaciones de plata son idénticos (Tissot et al., 2016b). Solo en una de las narigueras de este tipo se puede todavía ver en una pequeña región que la franja es, por lo menos actualmente, de color plateada (fig. 11b). El estudio por SEM-EDS de esta nariguera confirma la morfología totalmente distinta de las superficies de dos colores. La superficie de color marrón-negruzco (fig. 12) parece tener capas finas. El análisis por SEM-EDS muestra que la parte de oro tiene $80 \% \mathrm{Au}, 19 \% \mathrm{Ag}$ y $1 \%$ Cu y la zona marrón-negruzco tiene $70 \% \mathrm{Ag}, 19 \% \mathrm{Au}$ y $1 \% \mathrm{Cu}$, pero se observa también la aparición del hierro que alcanza valores de 11\%. La presencia de tan gran cantidad de hierro podría explicar el color marrón —a veces marrón-rojo, dependiendo de la luz - que se encuentra mezclado con el negro, color estándar de la sulfuración de la plata. 


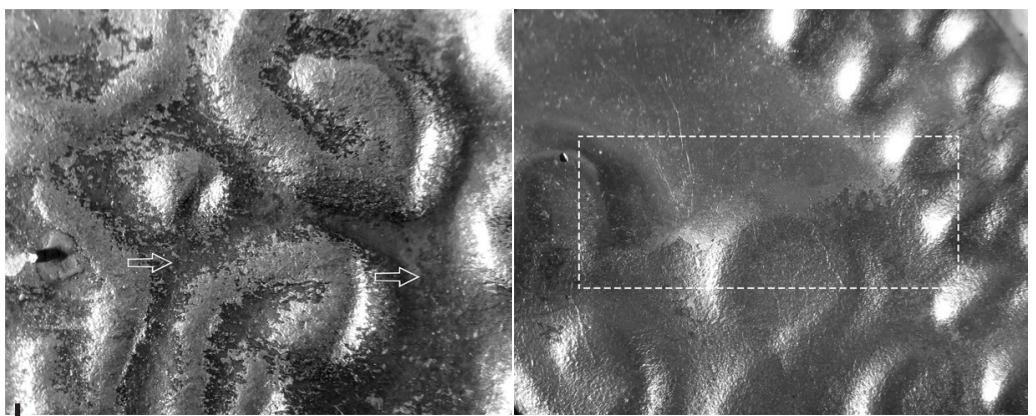

Figuras 11a y 11b - Regiones de la franja de color marrón-negruzco de la nariguera bicolor Poli 13, donde se puede ver (11a) los compuestos granulosos que evocan productos de corrosión y (11b) que el substrato parece ser blanco

(C) Imágenes M. F. Guerra

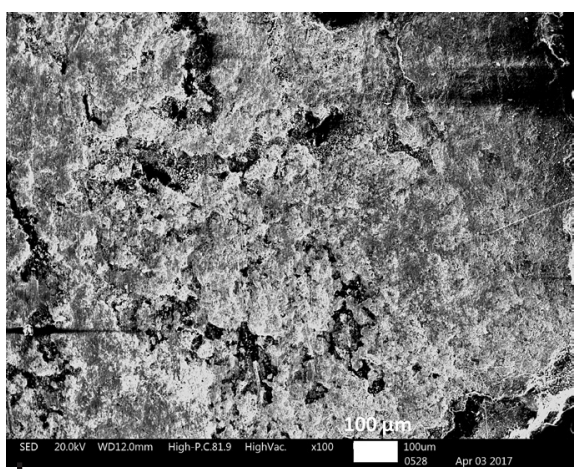

Figura 12 - Imagen SE (electrones secundarios) al SEM de la superficie de la franja de color marrón-negruzco de la nariguera bicolor Poli 13

(C) Imagen J. Ruiz

denso, como la plata o el cobre (Lang, 1997). Así, las franjas menos densas en la radiografía de la figura 13 podrían ser explicadas por la ausencia de una capa de oro en la superficie de la nariguera.

Los datos obtenidos para la nariguera Poli 13 parecen coincidir con una elaboración compleja a partir de una lámina en aleación de plata y oro que fue dorada. Las dos franjas de otro color podrían haber sido confeccionadas de varias maneras. Con los datos analíticos que tenemos actualmente no es posible proponer cuál fue la tecnología
La radiografía $X$ de la nariguera Poli 13 (fig. 13) muestra dos densidades distintas en la placa, como si fueran láminas en un metal distinto que constituyen las franjas. Se debe considerar que, para las mismas variables de exposición, la alta densidad del oro $\left(19,3 \mathrm{~kg} / \mathrm{dm}^{3}\right.$ contra $10,5 \mathrm{~kg} / \mathrm{dm}^{3}$ para la plata y 8,9 $\mathrm{kg} / \mathrm{dm}^{3}$ para el cobre) lleva a un cambio inmediato de la imagen radiográfica por rayos $X$, principalmente cuando se emplean tensiones de exposición bajas; de la misma forma ocurre si hay solo una fina capa en la superficie de una lámina elaborada en un metal menos

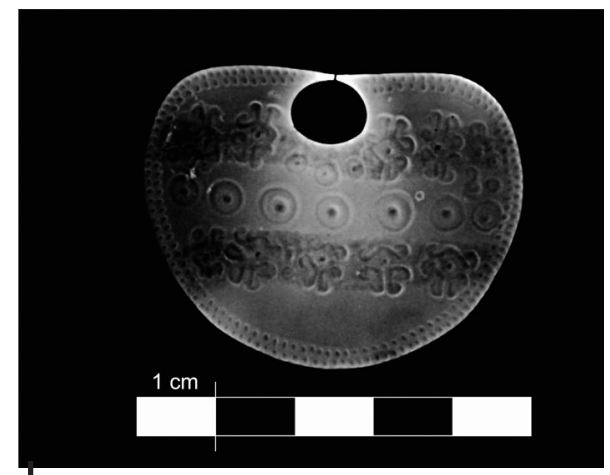

Figura 13 - Radiografía $X$ de la nariguera Poli 13 (270 kV de tensión, 0,2 mA y 2 s de tiempo de exposición)

(C) Imagen J. Ruiz 
empleada para elaborar esas narigueras, pero una posibilidad es cubrir la lámina con dos franjas de resina antes de hacer el dorado y después atacar con ácidos para cambiar el color, técnica utilizada en Colombia precolombina para producir objetos polícromos (Plazas de Nieto, 1977-1978). Es eventualmente posible completar el proceso con una capa de óxidos de hierro para obtener el color «rojo». El estudio de otras narigueras bicolores del mismo tipo y un estudio más profundo por medio de SEM-EDS permitirán abordar en el futuro el tema de las técnicas de policromía utilizadas en la elaboración de las narigueras.

\section{REFLEXIONES FINALES}

Las narigueras, símbolo de prestigio y poder en las culturas precolombinas peruanas, fueron confeccionadas desde el Horizonte Temprano, y en particular durante el Periodo Intermedio Temprano, en oro o plata, y a veces en una combinación de ambos metales. Usadas en vida durante las ceremonias rituales y también incluidas en los ajuares funerarios, estos adornos formaban parte de la gran parafernalia metálica con que se ataviaban los individuos pertenecientes a la élite, desde los chavín hasta los incas.

Las excavaciones de contextos mochica, frías, vicús, sicán y chimú, han revelado un abundante número de narigueras de varias tipologías y tamaños, manufacturadas empleando múltiples tecnologías orfebres, siendo unas de oro, otras de plata, aun de tumbaga y de cobre o incluso de dos colores. Sin embargo, la gran mayoría de narigueras presentes en las colecciones peruanas carece de procedencia conocida. En el área andina, así como en muchas partes del mundo, la extracción ilícita de material arqueológico dificulta su estudio por cuanto los contextos son destruidos, y con esto la información que contienen. En ese sentido, conocer la ubicación de los objetos dentro de los contextos, como podría ser un contexto funerario, es importante para el arqueólogo porque con ello podría determinar la importancia, el «uso», etc., del objeto en cuestión. Además, permite identificar la jerarquía del poseedor de dichos objetos por el tipo de pieza, material, iconografía y tecnología.

Por estas razones, estudiar objetos arqueológicos provenientes de excavaciones ilícitas es bastante difícil, sobre todo si se quiere determinar cuáles fueron los estilos en los que se fabricaron estas piezas y a qué sociedades pertenecieron. Las formas, comparaciones iconográficas y la tecnología ayudan al estudio de las piezas sin contexto conocido, siendo la procedencia geográfica el único dato disponible en algunos casos. Este es el caso de la gran mayoría de las narigueras.

Con excepción de las raras publicaciones que incluyen análisis con técnicas fisicoquímicas y proporcionan indicios sobre las tecnologías empleadas para elaborar narigueras procedentes de contextos específicos, no se conocen las técnicas de manufactura, incluso para lograr los colores de las narigueras bicolores. Por ello realizamos un primer estudio tecnológico de algunas narigueras de la costa norte peruana del Periodo Intermedio Temprano, analizando 39 de estos objetos pertenecientes a distintas colecciones peruanas, siendo 23 bimetálicas y 16 de 
oro. Debido a que las narigueras no provienen de excavaciones arqueológicas, recurrimos al «estilo» para separarlas en tres grupos de acuerdo a su forma e iconografía: estilo Mochica, estilo Vicús y estilo Mochica/Vicús. Los datos analíticos obtenidos para las aleaciones de las narigueras de oro no permiten distinguir entre estilos, pero los datos obtenidos para las narigueras bicolores muestran que algunos de esos ejemplares fueron elaborados con láminas de oro y plata unidas a veces por soldadura (en algunos casos probablemente debido a su restauración) y otras veces con una técnica de unión por martillado que podría ser idéntica a la que fue identificada en algunas piezas de Loma Negra.

No fue posible verificar las hipótesis propuestas para las narigueras bicolores, pues los equipos portátiles tienen limitaciones, en particular para estudios de superficies o pequeñas áreas. Dado que en la mayoría de los casos no es posible mover los objetos, o no se puede retirar una muestra, una de las narigueras bicolores fue seleccionada para otros estudios. A partir de su radiografía por rayos $X$ y de los resultados obtenidos para su superficie por medio de SEM-EDS, fue posible plantear algunas hipótesis sobre su manufactura, pero para comprobarlas se requiere un estudio más detallado de su superficie. En efecto, para entender mejor las narigueras bimetálicas, sobre todo las que pueden tener un tratamiento superficial, se debe realizar análisis con técnicas que tengan una buena resolución espacial y que permitan obtener perfiles elementales en superficie y en profundidad. Otra posibilidad es retirar una muestra para un pequeño conjunto de narigueras seleccionadas a partir de los resultados obtenidos con las técnicas portátiles en esta primera aproximación a su estudio tecnológico.

\section{Agradecimientos}

Agradecemos a la Colección Poli, al Museo Nacional de Arqueología, Antropología e Historia del Perú, al Museo del Banco Central de Reserva del Perú y al Museo de Oro y Armas del Mundo por permitirnos estudiar parte de su acervo. A Natalia Cisneros, por la búsqueda de bibliografía.

\section{Referencias citadas}

ALVA, I., 2012 - Los símbolos de Sipán. In: Tesoros preincas de la cultura Mochica. El Señor de Sipán, Huaca de la Luna y la Señora de Cao (L. Hurtado Rodríguez, ed.): 57-75; Lima: Fundación Augusto N. Wiese.

ALVA, W., 2015 - Sipán. Descubrimiento e investigación, 223 pp.; Lambayeque: ed. del autor.

BENÍTEZ TURRUBIATES, A., 2017 - Eterno, 41 pp.; Puebla: Universidad Iberoamericana. Disponible en http://repositorio.iberopuebla.mx

BRAY, W., 2003 - Gold, Stone, and Ideology: Symbols of Power in the Tairona Tradition of Northern Colombia. In: Gold and Power in Ancient Costa Rica, Panama, and Colombia (J. Quilter \& J. W. Hoopes eds.): 301-344; Washington D.C.: Dumbarton Oaks Research Library and Collection. 
CARCEDO, P., 2017 - Reflexiones sobre la producción sicán y chimú de vasos tipo kero y discos en plata: su iconografía y su relación con las miniaturas chimú. Bulletin de I'Institut français d'études andines, 46 (1): 37-75.

CARCEDO, P., GUERRA, M. F. \& VETTER, L., 2013 - La orfebrería de Frías. Estudios preliminares de tecnologías de elaboración y aleaciones. In: IV Simposio Latinoamericano de Física y Química en Arqueología, Arte y Conservación de Patrimonio Cultural. LASMAC 2013; Bogotá. 16 al 18 de octubre. CD-ROM.

CASTILLO NARREA, L. E. \& FERNÁNDEZ, D., 2017 - Los tesoros del Museo. Colección de Metales, 136 pp.; Lima: Ministerio de Cultura-Museo Nacional de Arqueología, Antropología e Historia del Perú.

CESAREO, R., BUSTAMANTE, A., AZEREDO, S., LOPES, R. T., FRANCO JORDÁN, R., FERNÁNDEZ, A. \& GIGANTE, G. E., 2017 - Radiography and transmission measurements on gold and silver from the moche tomb 'Señora de Cao'. Radiology and Diagnostic Imaging, 1 (1): 1-6.

CESAREO, R., FRANCO JORDÁN, R., FERNÁNDEZ, A., BUSTAMANTE, A., FABIÁN, J., ZAMBRANO S del P., AZEREDO, S., LOPES, R. T., INGO, G. M., RICCUCCI, C., DI CARLO, G. \& GIGANTE, G. E., 2016 - Analysis of the spectacular gold and silver from the Moche tomb 'Señora de Cao'. X-Ray Spectrometry, 45 (3): 138-154.

CIEZA DE LEÓN, P., 1984 - Crónica del Perú. Primera Parte, liv + 352 pp.; Lima: Fondo Editorial de la Pontificia Universidad Católica del Perú, Academia Nacional de Historia.

DONNAN, C. B., 2007 - Moche Tombs at Dos Cabezas, xii + 242 pp.; California: Cotsen Institute of Archaeology at UCLA. Monograph 59.

DONNAN, C. B. \& MCCLELLAND, D., 1999 - Moche fineline painting. Its evolution and its artist, 320 pp.; Los Ángeles: UCLA, Fowler Museum of Cultural History.

FALCHETTI, A. M., 1997 - La ofrenda y la semilla: notas sobre el simbolismo del oro entre los Uwa. Boletín Museo del Oro. Bogotá, 43: 3-37; Bogotá.

FRANCO, R., 2012 - El Complejo el Brujo: poder, arte, simbolismo y la tumba de la Señora de Cao. In: Tesoros preíncas de la cultura Mochica. El Señor de Sipán, Huaca de la Luna y la Señora de Cao (L. Hurtado Rodríguez, ed.): 77-109; Lima: Fundación Augusto N. Wiese.

GARCILASO DE LA VEGA, I., 1985 [1609] - Comentarios reales de los incas, volumen 1 518 pp.; Lima: Ediciones del Centenario-Banco de Crédito del Perú. Biblioteca Clásicos del Perú.

GUAMAN POMA DE AYALA, F., 1993 - Nueva corónica y buen gobierno, 3 vols. (F. Pease, ed.); México D.F.: Fondo de Cultura Económica.

GUERRA, M. F., 2008 - An overview on the ancient goldsmith's skill and the circulation of gold in the past: the role of x-ray based techniques. X-Ray Spectrometry, 37 (4): 317-327.

GUERRA, M. F., 2018 - El trabajo de los metales preciosos en el área andina: aportes arqueométricos. In: Arqueometría, estudios analíticos de materiales arqueológicos (R. Chapoulie, M. Sepúlveda, N. Del-Solar-Velarde \& V. Wright, eds.): 507-524; Lima: Institut Français d'Études Andines, Université de Bordeaux Montaigne, Universidad de Tarapacá.

GUZMÁN LADRÓN DE GUEVARA, C. \& CASAFRANCA, J., 1964 - Vicús. Informaciones arqueológicas I, 33 pp.; Lima: Comisión Nacional de Cultura.

HÖRZ, G. \& KALLFASS, M., 1998 - Pre-Columbian Metalworking in Peru - Ornamental and Ceremonial Objects from the Royal Tombs of Sipán. Journal of Metals, 50 (12): 8-16. 
JIMÉNEZ BORJA, A., 1998 - Vestidos populares peruanos, 251 pp.; Lima: Fundación del Banco Continental para el Fomento de la Educación y la Cultura.

LANG, J., 1997 - Metals. In: Radiography of Cultural Material (J. Lang \& A. Middleton eds.): 33-59; Oxford: Butterworth-Heinemann.

LECHTMAN, H., 1979 - A Pre-Columbian Technique for Electrochemical Replacement Plating of Gold and Silver on Copper Objects. Journal of Metals, 31 (12): 154-160.

MONTELL, G., 1929 - Dress and ornaments in ancient Peru, 262 pp.; Gotemburgo: Elanders Boktryckeri Aktiebol AG. Archaeological and Historical Studies.

MURÚA, M. de, 2001 - Historia general del Perú, 571 pp.; Madrid: Las Rozas. Crónicas de América, 20.

NOTIS, M. R., SHUGAR, A. N. \& NEWBURY, D. E., 2005 - Electrons, X-rays and Archaeometallurgy. Microscopy and Microanalysis, 11 (S02): 1360-1361.

ONUKI, Y., 1997 - Ocho tumbas especiales de Kuntur Wasi. Boletín de Arqueología PUCP, 1: 79-114.

PARRA BENAVIDES, O., 2016 - El gesto animal y el objeto humano: Construcción de narrativas y prácticas corporales en las narigueras Yotoco, Malagana y Sonso, 106 pp.; Bogotá: Universidad Nacional de Colombia, Facultad de Ciencias Humanas, Departamento de Antropología - Sede Bogotá. Tesis de Maestría en Antropología.

PINEDA CAMACHO, R., 2005 - El laberinto de la identidad: símbolos de transformación y poder en la orfebrería prehispánica de Colombia. In: Oro de Colombia, chamanismo y orfebrería: 17-92; Santiago de Chile y Bogotá: Museo Chileno de Arte Precolombino, Museo del Oro. Catálogo de la exposición, mayo-julio de 2005.

PLAZAS DE NIETO, C., 1977-1978 - La orfebrería prehistórica del altiplano Nariñense, Colombia. Revista Colombiana de Antropología, 21: 197-244.

PLAZAS DE NIETO, C., 1998 - Cronología de la metalurgia colombiana. Boletín Museo del Oro, 44-45: 2-77; Bogotá.

PLAZAS, C., 2007 - La metalurgia del Área Intermedia Sur dentro del Panorama Americano. International Journal of South American Archaeology, 1: 33-38.

PLAZAS DE NIETO, C. \& FALCHETTI, A. M., 1978 - Orfebrería prehispánica de Colombia. Boletín Museo del Oro, 3: 1-53; Bogotá.

RÍOS, M. \& RETAMOSO, H., 1993 - Investigaciones sobre la metalurgia vicús. Gaceta Arqueológica Andina, 7 (23): 33-66; Lima: Instituto Andino de Estudios Arqueológicos.

SÁENZ SAMPER, J., 1993 - Mujeres de barro: estudio de las figurinas cerámicas de Montelíbano. Boletín Museo del Oro: 34-35: 77-109; Bogotá.

SÁENZ-SAMPER, J. \& MARTINÓN-TORRES, M., 2017 - Depletion gilding, innovation and life-histories: the changing colours of Nahuange metalwork. Antiquity, 91 (359): 1253-1267.

SCHORSCH, D., 1998 - Silver and Gold Moche Artifacts from Loma Negra, Peru. Chicago Journals, Metropolitan Museum Journal, 33: 109-136; Chicago.

SCHORSCH, D., 2014 - A Conservator's Perspective on Ancient Metallurgy. In: Archaeometallurgy in Global Perspective. Methods and Syntheses (B. J. Roberts \& C. P. Thornton, eds.): 269-301; Nueva York: Springer-Verlag.

SCHORSCH, D., HOWE, E. G. \& WYPYSKI, M., 1996 - Silvered and gilded copper metalwork from Loma Negra: manufacture and aesthetics. Boletín Museo del Oro, 41: 144-163; Bogotá. 
SHIMADA, I., 1995 - Cultura Sicán. Dios, riqueza y poder en la costa norte del Perú, xiii + 219 pp.; Lima, Fundación del Banco Continental para el fomento de la educación y la cultura- EDUBANCO.

SOLÍS DEL VECCHIO, F. \& HERRERA VILLALOBOS, A., 2011 - Mesoamericanos en la Bahía de Culebra, noroeste de Costa Rica. Cuadernos de Antropología, 21: 1-31.

TISSOT, I., MONTEIRO, O. C., BARREIROS, M. A., CORREGIDOR, V., CORREIA, J. \& GUERRA, M. F., 2016a - Corrosion of silver alloys in sulphide environments: a multianalytical approach for surface characterization. Royal Society of Chemistry Advances, 6: 51856-51863.

TISSOT, I., MONTEIRO, O. C., BARREIROS, M. A., CORREIA, J. \& GUERRA, M. F., 2017 - The influence of the constituent elements on the corrosion mechanisms of silver alloys in sulphide environments: the case of sterling silver. Royal Society of Chemistry Advances, 7: 28564-28572.

TISSOT, I., MONTEIRO, O. C., BARREIROS, M. A. \& GUERRA, M. F., 2016b - Atmospheric corrosion of patinated silverwork: a conservation challenge. Corrosão e Protecção de Materiais, 35 (2): 15-19.

TROALEN, L. \& GUERRA, M. F., 2016 - Gold from the tomb of Scribe Beri: a comparative analytical approach to the New Kingdom gold grave goods from Riqqa (Egypt). Applied Physics, 122: 210.

VELA, E., 2015 - La joyería en el México antiguo. Arqueología Mexicana. Catálogo visual. Edición Especial 63.

VETTER, L., 2014 - El estilo Frías en Ayabaca, Piura y su relación con la orfebrería de los Andes Septentrionales; Lima: Universidad Nacional Federico Villarreal. Trabajo de investigación arqueológica para optar el título de Licenciada en Arqueología en la modalidad de suficiencia profesional

VETTER, L., 2017 - Nuevas aproximaciones al entendimiento del material metálico de Frías en Piura. In: Actas del II Congreso Nacional de Arqueología 2: 179-190; Lima, Ministerio de Cultura. 